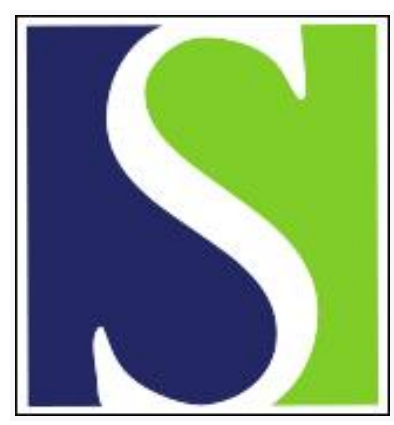

Scand J Work Environ Health 2007;33(4):260-266

https://doi.org/10.5271/sjweh.1141

Issue date: 31 Aug 2007

Physiological and psychological stress reactions in relation to classroom noise

by Wålinder R, Gunnarsson K, Runeson R, Smedje G

Affiliation: Department of Medical Sciences and Occupational and Environmental Medicine, University Hospital, SE-751 85 Uppsala,

Sweden. robert.walinder@medsci.uu.se

The following article refers to this text: 2010;36(3):250-257

Key terms: blood pressure; child; classroom noise; cortisol; emotional indicator; headache; noise; physiological stress reaction; physiology; psychological stress reaction; psychology; school; stress

This article in PubMed: www.ncbi.nlm.nih.gov/pubmed/17717617

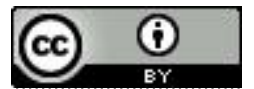




\title{
Physiological and psychological stress reactions in relation to classroom noise
}

\author{
by Robert Wålinder, PhD, ${ }^{1}$ Kristina Gunnarsson, ${ }^{1}$ Roma Runeson, PhD, ${ }^{1}$ Greta Smedje, PhD ${ }^{1}$
}

\begin{abstract}
Wålinder R, Gunnarsson K, Runeson R, Smedje G. Physiological and psychological stress reactions in relation to classroom noise. Scand J Work Environ Health 2007;33(4):260-266.
\end{abstract}

\begin{abstract}
Objectives This study tested the hypothesis that classroom noise is related to stress reactions among primary school children. Stress was monitored via symptoms of fatigue and headache, systolic blood pressure, reduced diurnal cortisol variation, and indicators of emotional distress.

Methods In three classrooms of pupils in the fourth grade (10 years of age), daily measurements of equivalent sound levels (Leq) were made during 4 weeks, evenly distributed from September to December. One day each week of the study, the pupils answered a questionnaire about disturbance and symptoms, and blood pressure and salivary cortisol were measured. In the first and fourth week, the children also performed a standardized drawing test concerning emotional indicators.

Results Daily measurements of equivalent sound levels in the classes (Leq during schoolday) ranged from 59 to $87 \mathrm{~dB}(\mathrm{~A})$. Equivalent sound-levels were significantly related to an increased prevalence of symptoms of fatigue and headache and a reduced diurnal cortisol variability. Blood pressure and emotional indicators were not significantly related to sound levels.

Conclusions Current sound levels in Swedish classrooms may have a negative health impact, being directly or indirectly related to stress reactions among children. This finding indicates that noise should be focused on as a risk factor in the school environment.
\end{abstract}

Key terms blood pressure; children; cortisol; emotional indicator; headache; noise; physiology; psychology; school; stress.

Current occupational limits for noise are set for the prevention of hearing impairment. There are, however, several other unwanted effects of chronic noise exposure below the occupational limits. An increased risk of cardiovascular disease has been shown for environmental noise exposure from of $65-70 \mathrm{~dB}(1,2)$. Noise levels in classrooms are dependent on both outdoor sources, such as road traffic by the school, and indoor sources, such as sound from building installations. However, noise levels are strongly dependent upon the activities in which the children are engaged (3). Most studies on the nonauditory effects on children of environmental noise involve exposure to community noise (4). Children exposed to traffic noise above $60 \mathrm{~dB}$ had increased blood pressure and cortisol levels $(1,5,6)$. In addition, self-reported mental well-being has been rated lower by children exposed to higher levels of community noise (7). In the pedagogic field, noise, defined as unwanted sound, has well-known negative effects on hearing ability in schools (8). Noise also affects concentration $(9,10)$, performance (11), reading, and memory (12-14). In a Swedish study on secondary schoolchildren, one-third of the participants reported that existing sound levels from classroom noise, range 58-69 dB(A), obstructed their work (15), and they were the most annoyed by chatter in the classroom and scraping sounds from tables and chairs. Emotional effects, such as aggressive (16) or opposing (10) behavior, have also been found to be related to noise exposure.

In human figure drawings, Koppitz (17) found 28 signs that indicated emotional problems, so-called emotional indicators (17). Effects of acute stress and preparation for stress on emotional indicators in drawings were found in drawings by 4-to-12-year-old children that were hospitalized for elective surgery. The emotional indicators increased only in the group that was stressed and unprepared (18). The effects of naturally occurring stress on emotional indicators have not been studied earlier. One such naturally stressful situation may be the noise in a classroom.

1 Department of Medical Sciences and Occupational and Environmental Medicine, University Hospital, Uppsala, Sweden.

Reprint requests to: Dr R Wålinder. Department of Medical Sciences and Occupational and Environmental Medicine, University Hospital, SE-751 85 Uppsala, Sweden. [E-mail: robert.walinder@medsci.uu.se] 
The measurement of salivary cortisol has been shown to be a reliable and noninvasive method appropriate for field studies and studies among children $(19,20)$. The adrenal cortical hormone cortisol normally has diurnal variability, with a morning peak and midday dip (21-25). In infants the pattern is different, but, among 10 -year-olds, the adult pattern is present $(21,25)$. In the 1950s it was shown that this diurnal variability was reduced in psychiatric patients with severe emotional distress (26), and a similar pattern has been shown due to stress and anxiety (24). There may also be a seasonal change in cortisol levels $(21,27)$.

The aim of our study was to determine whether stress-related symptoms and signs are related to sound levels in the classroom. The sound level was assumed to be both a direct stressor and also an indirect measure of other stressors such as crowdedness and turbulence. Apart from higher blood pressure, increased headache, and fatigue and more emotional indicators, it was assumed that a stressful school environment would show a reduced difference between the morning peak cortisol level and the midday dip, or even a reversed pattern with a higher midday value than a morning value.

The study was performed after written consent was obtained from the pupils and their parents and after approval by the regional ethics committee at the University of Uppsala, Sweden.

\section{Study population and methods}

\section{Study design}

All of the pupils $(\mathrm{N}=78)$ in the fourth grade (10 years of age) in two primary schools (3 classes) were asked to participate. Altogether 57 (73\%) participated after written consent was obtained from both the pupils and the parents. The two schools had adjacent catchment areas in central Uppsala with similar socioeconomic conditions. A standardized scheme of measurements was applied during the 4 weeks of the investigation, with the 4 weeks evenly distributed from September to December. Sound-level measurements were performed each day during these four weeks. Questionnaires and physiological measurements were made once a week on the same day, in the same order, and at the same time. The drawing was performed during the first and last week of the investigation at the same time and on the same day as the physiological measurements. Due to sick leave, 4, 3, 1, and 3 pupils were absent during weeks $1,2,3$, and 4 , respectively.

\section{Noise measurements}

Noise in the classrooms was monitored with parallel measurements in the three classes. Integrating sound-level meters were employed. They were type-1 sound-level meters capable of giving a continuous readout of the noise-level readings, including the equivalent continuous sound-pressure level (Leq). In two of the classrooms, sound-level meters, type 2260 (Brüel \& Kjær Ltd, Nærum, Denmark), were used, and, in the third, a real-time analyzer, Nor SA110 (Norsonic AS, Trier, Norway), was used. All of the meters were calibrated before each measurement period. The sound-level meters were placed in the middle of the classrooms at about a height of 1 meter. The measurements started in the morning before class and stopped at the end of the school day, recording the equivalent sound level for each second. Including only the time that the class actually spent in the classroom (thus excluding breaks, etc), the equivalent sound level for each school day was calculated. The time spent in the classroom varied between 3 and 5 hours per day, but was mostly around 4 hours.

\section{Assessment of disturbance and symptoms}

Self-reported disturbance and symptoms due to noise in the classroom were assessed using a questionnaire with five questions rated from 1 to 5. [See the appendix.] The pupils were given oral instructions to report their status that day, and every rated answer had a face representing the rated feeling also attached. The stressors were classified as hearing difficulties (Q1), disturbance (Q 2), fatigue (Q 3), headache (Q 4), and reading difficulties (Q 5). These five questions were administered once at the same time (last lesson before the lunch break) and on the same weekday every week of the study.

\section{Physiological parameters}

Blood pressure was measured on the right arm manually with a stethoscope and a sphygmomanometer with the pupil sitting during the last lesson before the lunch break. Heart rate was assessed from the arterial radial pulse. Salivary cortisol was sampled by a standardized procedure with a cotton wad (Department of Clinical Chemistry, University Hospital, Uppsala) during the first lesson in the morning and the last lesson before lunch, and the difference between the two measurements was calculated to assess the diurnal variability from the morning peak to the lunch dip.

\section{Assessment of emotional indicators}

The children were asked to draw a human figure drawing according to Koppitz's original instruction "Draw one whole person. You can draw any kind of person you want to draw, but not a stick figure". The pupils were provided with a blank sheet of paper, size 8.5 by 11 inches ( 21.6 by $27.9 \mathrm{~cm}$ ), and a number 2 pencil with an eraser. Drawings were made at the same time and on the same weekday during the first and the fourth week 
of the investigation. The drawings were rated on a "yes" and "no" basis, using the 28 emotional indicators (18). The rating was performed by two licensed psychologists both trained in the use of projective drawings. In the rating of the drawings, one of the raters was blind to the purpose of our study, and both raters were blind to the participant's scores on other measures. The emotional indicators were grouped into the following five categories (i) impulsivity, (ii) insecurity, (iii) anxiety, (iv) shyness, and (v) aggressiveness (18).

\section{Statistical analysis}

Spearman's rank correlation coefficients were calculated for the bivariate relationship between noise exposure and the ordinal outcome of the ratings in the questionnaire and of the drawings. The median values of each participant for weeks 1 to 4 were applied to control intraindividual variability. Kendall's rank correlation was used for the interrater reliability test of drawings. For the blood pressure and cortisol a linear mixed model with random intercept was used for the 4-week longitudinal analysis of the relation to noise (28). SAS statistical package, version 9.1.3 (SAS Institute, Cary, NC, USA) was used.

\section{Results}

\section{Sound levels}

In two classes there was a 1-day holiday during one of the measurement periods, and on 2 days the measurements

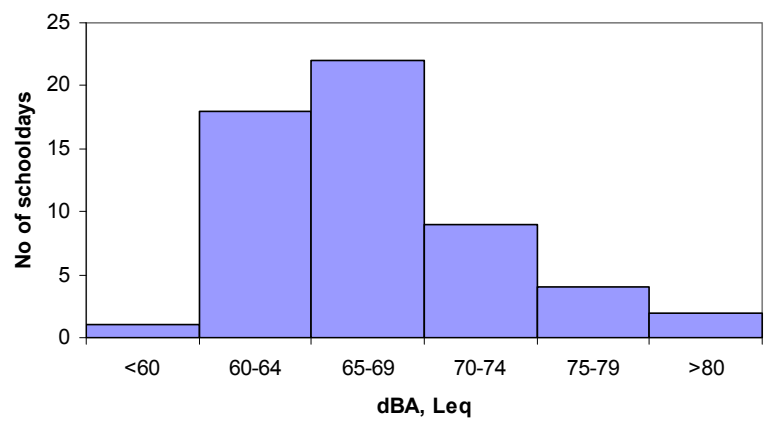

Figure 1. Frequency diagram of equivalent sound levels (Leq during the schoolday) ranging from 59 to $87 \mathrm{~dB}(\mathrm{~A})$ during the 56 days of measurement. failed in one class due to technical problems. Thus there were 56 measurements of schoolday sound levels. The equivalent sound levels for the 56 days ranged from 59 to $87 \mathrm{~dB}(\mathrm{~A})$ (figure 1). On most of the school days the equivalent sound level was between 60 and $70 \mathrm{~dB}(\mathrm{~A})$. However, on 15 days, the equivalent sound level exceeded $70 \mathrm{~dB}(\mathrm{~A})$, and, on 2 days, it was higher than 80 $\mathrm{dB}(\mathrm{A})$. In one of the classrooms, the background level of the empty classroom was $33 \mathrm{~dB}(\mathrm{~A})$, and, in the other two, it was $37 \mathrm{~dB}(\mathrm{~A})$.

\section{Questionnaire}

All five questions were significantly related to the measured sound levels. The question about the ability to hear the teacher due to noise in the classroom had a correlation coefficient of 0.65 with respect to measurements of daily and weekly equivalent sound levels (table 1). The other four questions (about symptoms and performance) had correlation coefficients from 0.3 to 0.4 with respect to sound levels. The median rating of the questions for the 4 weeks altogether was 2 (seldom versus a little bit difficult) on a scale from 1 to 5 . [See the appendix.] The boys reported more difficulty hearing the teacher with a median rating of 3 (sometimes) than the girls with a median rating of 2 (seldom). The girls reported more symptoms of headache, with a median rating of 2 (seldom) than the boys with a median rating of 1 (never). Median ratings were unchanged over the 4 weeks.

\section{Physiological measurements}

The mean systolic blood pressure for all 4 weeks was 96 (boys 98, girls 94 , SD 8 ) mm $\mathrm{Hg}$ and was numerically, but not significantly, higher as the sound level increased. Diastolic pressure was not related to the sound level (mean $62 \mathrm{~mm} \mathrm{Hg}$, SD $7 \mathrm{~mm} \mathrm{Hg}$ ). The mean morning salivary cortisol level for all 4 weeks was 5.6 (SD 5.0, range 1.5-42 ) nanograms and the midday level was 3.9 (SD 3.3, range 0.9-30) nanograms. A linear correlation for all of the cortisol measurements, with four repeated measurements for each pupil, showed a significant correlation with decreased variability with higher sound levels (figure 2). Control for intraindividual variability longitudinally in a mixed linear model, both with and

Table 1. Correlation coefficients between five questions ${ }^{\text {a }}$ and the equivalent daily sound levels.

\begin{tabular}{|c|c|c|c|c|c|c|c|c|c|c|}
\hline & \multicolumn{2}{|c|}{ Question 1} & \multicolumn{2}{|c|}{ Question 2} & \multicolumn{2}{|c|}{ Question 3} & \multicolumn{2}{|c|}{ Question 4} & \multicolumn{2}{|c|}{ Question 5} \\
\hline & $\begin{array}{l}\text { Spearman's } \\
\text { correlation } \\
\text { coefficient }\end{array}$ & P-value & $\begin{array}{c}\text { Spearman's } \\
\text { correlation } \\
\text { coefficient }\end{array}$ & P-value & $\begin{array}{l}\text { Spearman's } \\
\text { correlation } \\
\text { coefficient }\end{array}$ & P-value & $\begin{array}{l}\text { Spearman's } \\
\text { correlation } \\
\text { coefficient }\end{array}$ & P-value & $\begin{array}{l}\text { Spearman's } \\
\text { correlation } \\
\text { coefficient }\end{array}$ & P-value \\
\hline $\operatorname{Leq}^{b}(\mathrm{dBA})$ & 0.65 & $<0.01$ & 0.31 & 0.02 & 0.41 & $<0.01$ & 0.29 & 0.03 & 0.27 & 0.04 \\
\hline
\end{tabular}

a Questions 1-5; see the appendix.

b Equivalent sound level during the day the questionnaire was administered. 
Scatterplot of sound level to cortisol difference (morning level minus midday level)

Linear estimate:

Cortisol difference $=8.8-0.1 x ;$ w ith $\quad 95 \%$ Conf. Int

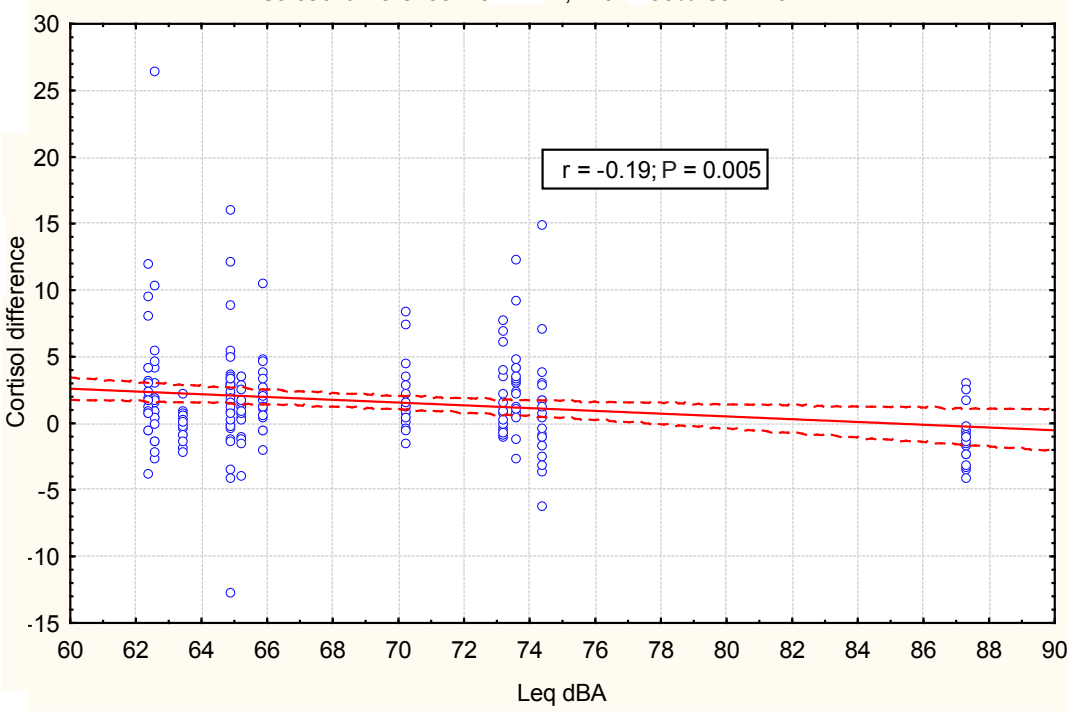

Figure 2. Scatterplot of the relation between the equivalent sound level during the day and the change in cortisol level from morning to noon. The diurnal variation in the cortisol levels normally shows a morning peak and a midday dip. A stress response due to noise during the schoolday was assumed to reduce this difference or even to give a reverse pattern with a higher midday level than a morning level. A linear estimate shows that midday cortisol was higher than the morning level for sound levels exceeding $85 \mathrm{dBA}$. without outliers, strengthened this association (table 2). The mean pulse rate was 78 (SD 9) beats per minute. Pulse rate was negatively correlated with noise level ( $r-0.20$ with a linear correlation and also significant in a mixed linear model). There was no significant correlation between blood pressure and the cortisol levels and no significant gender difference for noise effect on the cortisol levels. The trend over time showed a greater midday dip when compared with the morning value at the end of the term.

\section{Emotional indicators}

The emotional indicators were not significantly related to the sound levels, the correlation coefficients ranging from 0.01 to 0.2 . The mean interrater reliability, calculated as a correlation of the 28 emotional indicator signs, for the two raters' scores was $0.92(\mathrm{P}<0.001$, by Kendall's rank correlation). There was a trend over time from the first week of study to the fourth week of study according to which emotional indicators of impulsiveness, insecurity, anxiety, and aggressiveness increased, whereas indicators of shyness decreased. At the beginning of the term, there was no gender difference, but, at the end of the term, the boys had significantly higher mean ratings for impulsiveness (boys 0.8 and girls 0.1 ), insecurity (boys 0.6 and girls 0.2 ), and shyness (boys 0.6 and girls 0.1 ).

\section{Discussion}

In our study, higher sound levels were associated with more symptoms of fatigue and headache together with
Table 2. Parameter estimates (Est) of the general linear mixed model, the standard errors (SE), and the P-values showing the relation between the change in the salivary cortisol concentration from morning to midday and the noise level over time.

\begin{tabular}{|c|c|c|c|c|c|c|}
\hline \multirow[t]{2}{*}{ Parameter } & \multicolumn{3}{|c|}{$\begin{array}{l}\text { Random intercept } \\
\text { model with outliers }\end{array}$} & \multicolumn{3}{|c|}{$\begin{array}{l}\text { Random intercept } \\
\text { model without outliers }\end{array}$} \\
\hline & Est & SE & P-value & Est & SE & P-value \\
\hline Intercept & 6.82 & 3.06 & 0.03 & 7.47 & 0.79 & 0.05 \\
\hline Leq $^{\text {a }}(\mathrm{dBA})$ & -0.10 & 0.04 & 0.02 & -0.11 & 0.05 & 0.04 \\
\hline Weeks & 0.59 & 0.21 & $<0.01$ & 0.65 & 0.20 & $<0.01$ \\
\hline
\end{tabular}

a Equivalent sound level during the day the questionnaire was administered.

reduced cortisol variability. These results are compatible with a stress response.

Altogether 2 of 56 daily equivalent sound-level measurements exceeded the present European occupational action limit of $80 \mathrm{~dB}(\mathrm{~A})$ (29), the highest being $87 \mathrm{~dB}(\mathrm{~A})$. There is always a possibility of measurement errors. However, we did not find any technical explanation or any other unusual circumstances during the days with the highest sound levels. Actually, we visited the classroom each day of measurement and also made enquiries among the teachers about the activities during the day. We regard the highest levels as reflecting the upper tail of a positively skewed distribution of daily measurements of sound levels (figure 1). The measurement periods were shorter than the 8 hours for which the standards are applicable, but there are indications that sound levels during other activities in school may be even higher. There are reports also from other European countries (ie, Poland) showing daily noise levels at school exceeding $80 \mathrm{~dB}(\mathrm{~A})$ and even higher values 
in the corridors during breaks [95-98 dB(A)] (30). An English study found that the average equivalent sound level in occupied classrooms was $72 \mathrm{~dB}(\mathrm{~A})$ (3). Both the World Health Organization (WHO) and the United States Environmental Protection Agency report that a daily equivalent sound level should not exceed $70 \mathrm{~dB}(\mathrm{~A})$ to be safe for the ear (31). Levels higher than $70 \mathrm{~dB}(\mathrm{~A})$ were measured on 15 of 56 days (26\%) in our study. Reports from The Swedish Work Environment Authority corroborates these results, showing noise levels between 66 and $77 \mathrm{~dB}(\mathrm{~A})$ in classrooms (32), and the authority has ordered improvements based on classroom noise levels exceeding $70 \mathrm{~dB}(\mathrm{~A})$.

Physiological or psychological effects other than hearing impairment can be expected at sound levels lower than the current occupational standards $(1,2)$. Apprehension and ability to hear in the classroom are affected at background noise levels exceeding $50 \mathrm{~dB}(\mathrm{~A})$, according to the recommendations of the Swedish Work Environment Authority (29). In a Swedish study on secondary school pupils, one-third of the participants reported their work was obstructed when measured noise levels were between 58 and $69 \mathrm{~dB}(\mathrm{~A})$ (15). A WHO report claims that background noise should not exceed $35 \mathrm{~dB}(\mathrm{~A})$ in order to ensure speech communication (with an ordinary voice level of $50 \mathrm{~dB}$ at a distance of 1 meter) $(2,33)$. Nonauditory cardiovascular effects of environmental noise have been detected at levels from 65 to $70 \mathrm{~dB}(\mathrm{~A})(2,4,34)$. There are reports indicating an increased risk of vocal cord dysfunction among teachers (35-37). A Danish survey among 5395 employees of different occupations showed that teachers had a (nonsignificant) numerically lower prevalence of hearing impairment but a numerically higher prevalence of tinnitus and increased sensitivity to sound (38).

Considering the possible day-to-day variation of sound levels, we measured the equivalent sound level during more schooldays (56 days, figure 1) than presented in the analyses of relationships between noise and stress effects (12 days, figure 2 ). In fact, we made the same statistical analyses also using the equivalent sound level during the week, and there were only minor differences in the results.

All of the questions on noise disturbance were significantly related to the measured noise levels, but the correlation coefficients were low. It has been shown earlier that the degree of disturbance is not only related to noise level, but also to different physical properties of sound, as well as to the source and information content of sound (39). However, the question about having difficulty to hear the teacher had a higher correlation. We conclude that this question is suitable for estimating noise levels that are too high in schools. One possible source of bias in the questions was that all of them were related to the current noise level in the classroom, the participants therefore being left to analyze the causes of the disturbance and the symptoms. There is a range of factors other than noise that cause, for instance, disturbance and headache, but, by focusing only on the contribution due to noise, other effect-modifying factors were diminished.

We measured cortisol as a marker of mental stress, but there are several other external factors that influence cortisol secretion. In adults, cortisol levels are influenced by smoking, alcohol, obesity, malnutrition, sleep, and physical exercise (40). Among 10-to-12-year-old children, gender influences salivary cortisol levels, but not prenatal factors, body mass index, or pubertal development (21). There is a great interindividual variability in cortisol levels $(21,25)$. Therefore, the diurnal variability could have been a more sensitive parameter when acute stress responses during the day were measured, and a reduced variability has been found to be related to perceived mental stress (24). Acute stress exposure stimulates the hypothalamic-pituitary-adrenal axis through the release of stress hormones, one of which is cortisol. Similarly a stressful school environment would increase the internal cortisol secretion and result in a reduced midday dip. We showed a significantly reduced midday dip with increasing sound levels in the classroom. According to our hypothesis, the midday value should reflect the acute stress response during the schoolday, which was assessed via the equivalent sound level that day. The morning peak was assumed to be independent of school activities, and previous studies have shown an intraindividually stable morning peak $(41,42)$. The cortisol awakening response and the diurnal values during the schoolday would therefore represent different sensitivity to acute stress during the day, during which the morning response is under genetic influences and the day values are under environmental influences $(43,44)$.

Symptoms of headache and fatigue were positively correlated with the sound levels. These symptoms are common in school health and are considered major psychosomatic symptoms in association with stress (45, 46), and also noise (47). These symptoms are also considered more prevalent among girls (48). A similar pattern was found in our study, in which the girls reported more symptoms of headache, whereas the boys reported more difficulty hearing the teacher. Another study found that girls, but not boys, were stressed by rowdiness in the classroom (49). Whereas subjective questionnaire ratings of disturbance and symptoms were unchanged during the study period, a trend was found over time for an increase in the emotional indicators impulsiveness, insecurity, anxiety, and aggressiveness. Only indicators of shyness decreased.

A recent report on Swedish schoolchildren has shown a large increase in stress-related symptoms during the last 20 years (50). Noise in the classroom may function 
as a direct stressor affecting apprehension, performance, and physiological stress responses. However, noise may also be a proxy for a turbulent environment in which factors other than noise may cause stress reactions (ie, crowded, violent, or hostile emotional climates). For the most part, these troubled conditions are associated with higher sound levels and noise; therefore it can be difficult to distinguish what might be the primary source for unwanted health effects. Furthermore, the type of sound can be relevant. When a person listens to music there is a lower cortisol response from other stressors (51). In our study, we registered the participants' heart rate, which directly reflects the level of physical activity. Since heart rate was negatively correlated with the noise level, the results indicate lower noise and possibly less stress if the pupils have lessons permitting some physical activity. However, our study was not aimed at studying factors other than noise as possible causes of stress reactions.

In conclusion, by considering noise in the classroom as either a direct stressor or a proxy variable for other troublesome conditions, we found positive correlations between equivalent sound levels and symptoms of fatigue, headache, and reduced diurnal cortisol variability. Since occupationally acceptable noise levels were also exceeded, both legal and medical arguments call for a reduction of noise levels in current Swedish classrooms. Smaller classes and sound-absorbing constructions and fittings could be examples of immediate actions. Additional studies are needed to decide whether noise itself or other factors associated with noise are responsible for the stress reactions observed.

\section{Acknowledgments}

We extend our thanks to the pupils for participating, the teachers and headmasters for their organizational help, Yahong Mi for performing the sound measurements, Margareta Fürst for coding the drawings, and Anders Berglund for carrying out the statistical calculations.

\section{References}

1. Babisch W. Traffic noise and cardiovascular disease: epidemiological review and synthesis. Noise Health. 2000;2(8):9-32.

2. World Health Organization (WHO). Occupational and community noise. Fact sheet No. 258. Geneva: WHO; 2001.

3. Schield B, Dockrell JE. External and internal noise surveys of London primary schools. J Acoust Soc Am. 2004;115(2):7308.

4. Berglund B, Lindvall T. Community noise: report to the World Health Organization: Archives of the Center for Sensory Research. Stockholm: Karolinska Institute; 1995.
5. Evans GW, Lercher P, Meis M, Ising H, Kofler WW. Community noise exposure and stress in children. J Acoust Soc Am. 2001;109(3):1023-7.

6. Passchier-Vermeer W, Passchier WF. Noise exposure and public health. Environ Health Perspect. 2000;108 suppl 1:123-31

7. Lercher P, Evans GW, Meis M, Kofler WW. Ambient neighbourhood noise and children's mental health. Occup Environ Med. 2002;59(6):380-6.

8. Jamieson DG, Kranjc G, Yu K, Hodgetts WE. Speech intelligibility of young school-aged children in the presence of real-life classroom noise. J Am Acad Audiol. 2004;15(7):508-17.

9. Evans GW, Lepore SJ. Nonauditory effects of noise on children: a critical review. Child Environ. 1993;10(1):31-51.

10. Ristovska G, Gjorgjev D, Pop Jordanova N. Psychosocial effects of community noise: cross sectional study of school children in urban center of Skopje, Macedonia. Croat Med J. 2004;45(4):473-6.

11. Bullinger M, Hygge S, Evans GW, Meis M, von Mackensen S The psychological cost of aircraft noise for children. Zentralbl Hyg Umweltmed. 1999;202(2-4):127-38.

12. Hygge S, Evans GW, Bullinger M. A prospective study of some effects of aircraft noise on cognitive performance in schoolchildren. Psychol Sci. 2002;13(5):469-74.

13. Clark C, Martin R, van Kempen E, Alfred T, Head J, Davies $\mathrm{HW}$, et al. Exposure-effect relations between aircraft and road traffic noise exposure at school and reading comprehension: the RANCH project. Am J Epidemiol. 2006;163(1):27-37.

14. Stansfeld SA, Berglund B, Clark C, Lopez-Barrio I, Fischer $\mathrm{P}$, Ohrstrom E, et al. Aircraft and road traffic noise and children's cognition and health: a cross-national study. Lancet. 2005;365(9475):1942-9.

15. Lundquist P, Holmberg K, Landström U. Annoyance and effects on work from environmental noise at school. Noise Health. 2000;2(8):39-46.

16. Berglund B, Lindvall T, Schwela DH. Guidelines for community noise. Geneva: World Health Organization; 2000.

17. Koppitz EM. Psychological evaluation of human figure drawings by middle school pupils. New York: Grune \& Stratton; 1984.

18. Sturner RA, Rothbaum F, Visintainer M, Wolfer J. The effects of stress on children's human figure drawings. J Clin Psychol. 1980;36(1):324-31.

19. Bigert C, Bluhm G, Theorell T. Saliva cortisol-a new approach in noise research to study stress effects. Int $\mathrm{J}$ Hyg Environ Health. 2005;208(3):227-30

20. Gustafsson PE, Gustafsson PA, Nelson N. Cortisol levels and psychosocial factors in preadolescent children. Stress Health. 2006;22:3-9.

21. Rosmalen JGM, Oldehinkel AJ, Ormel J, deWinter AF, Buitelar JK, Verhulst FC. Determinants of salivary cortisol levels in 10-12 year old children; a population-based study of individual differences. 2005;30(5):483-495.

22. Weitzman ED, Fukushima D, Nogeire C, Roffwarg H, Gallagher TF, Hellman L. Twenty-four hour pattern of the episodic secretion of cortisol in normal subjects. J Clin Endocrin Metab. 1971;33(1):14-22.

23. Edwards S, Clow A, Evans P, Hucklebridge F. Exploration of the awakening cortisol response in relation to diurnal cortisol secretory activity. Life Sci. 2001;68:2093-103.

24. Vedhara K, Miles J, Bennett P, Plummer S, Tallon D, Brooks $\mathrm{E}$, et al. An investigation into the relationship between salivary cortisol, stress, anxiety and depression. Biol Psychol. 2003;62(2):89-96. 
25. Knutsson U, Dahlgren J, Marcus C, Rosberg S, Brönnegård M, Stierna P, et al. Circadian cortisol rhythms in healthy boys and girls: relationship with age, growth, body composition, and pubertal development. J Clin Endocrinol Metab. 1997;82:536540.

26. Board F, Persky H, Hamburg D. Psychological stress and endocrine functions. Psychosom Med. 1956;18(4):324-33.

27. Weitzman ED, deGraaf AS, Sassin JF, Hansen T, Godtlibsen OB, Perlow M, et al. Seasonal patterns of sleep stages and secretion of cortisol and growth hormone during 24 hour periods in northern Norway. Acta Endocrinol (Copenh). 1975;78(1):65-76.

28. Fitzmaurice GM, Laird NM, Ware JH. Applied longitudinal analysis. Hoboken (NJ): John Wiley \& Sons, Inc; 2004. Wiley series in probability and statistics.

29. Arbetsmiljöverket (The Swedish Work Environment authority). Arbetsmiljöverkets författningssamling [Statutes of The Swedish Work Environment Authority]. Solna (Sweden): Arbetsmiljöverket, Publikationsservice; 2005. Noise 16.

30. Koszarny Z, Jankowsska D. Uwarunkowania klimatu akustycznego pomieszczen szkó [Determination of the acoustic climate inside elementary schools]. Rocz Panstw Zaki Hig. 1995;46(3):305-14.

31. Berglund B, Lindvall T, Schwela DH. Guidelines for community noise. Geneva: Department of the Protection of the Human Environment, Occupational and Environmental Health, World Health Organization; 2000.

32. Arbetsmiljöverket (The Swedish Work Environment authority). Elevers skolmiljö: arbetsmiljöstatistik [The pupil's school environment: work environment statistics]. Solna (Sweden): Arbetsmiljöverket, Publikationsservice; 2006. Report 3.

33. Lazarus H. New methods for describing and assessing direct speech communication under disturbing conditions. Environ Int. 1990;16:373-92.

34. Babisch W, Beule B, Schust M, Kersten N, Ising H. Traffic noise and risk of myocardial infarction. Epidemiology. 2005;16(1):33-40.

35. Simberg S, Sala E, Vehmas K, Laine A. Changes in the prevalence of vocal symptoms among teachers during a twelve-year period. J Voice. 2005;19(1):95-102.

36. Smith E, Kirchner HL, Taylor M, Hoffman H, Lemke JH. Voice problems among teachers: differences by gender and teaching characteristics. J Voice. 1998;12(3):328-34.

37. Vilkman E. Occupational safety and health aspects of voice and speech professions. Folia Phoniatr Logop. 2004;56(4):220 53.

38. Sperling BB, Lund SP, Burr H. Hörelse, arbetsmiljö i Danmark
2000 [Hearing, working environment in Denmark 2000]. Copenhagen: Holbaek Eksprestrykkeri; 2002.

39. Landström U, Arlinger S, Hygge S, Johansson Ö, Kjellberg A, Persson Waye K. Störande buller, kunskapsöversikt för kriteriedokumentation [Disturbing noise, review for criteria documentation]. Stockholm: National Institute of Working Life; 1999. Arbete och Hälsa 1999: 27.

40. Fukuda S, Morimoto k. Lifestyle, stress and cortisol response: review II. Environ Health Prev Med. 2001;6:9-14.

41. Wust S, Wolf J, Hellhammer DH, Federenko I, Schommer N, Kirschbaum C. The cortisol awakening response-normal values and confounds. Noise Health. 2000;2:79-88.

42. Clow A, Thorn L, Evans P, Hucklebridge F. The awakening cortisol response: methodological issues and significance. Stress. 2004;7:29-37.

43. Wust S, Federenko I, Hellhammer DH, Kirschbaum C. Genetic factors, perceived chronic stress, and the free cortisol response to awakening. Psychoneuroendocrinology. 2000;25: 707-720.

44. Bartels M, de Geus EJC, Kirschbaum C, Sluyter F, Boomsma DI. Heritability of daytime cortisol levels in children. Behav Genet. 2003;33:421-433.

45. Carlsson J, Larsson B, Mark A. psychosocial functioning in schoolchildren with recurrent headaches. Headache. 1996;36(2):77-82.

46. Metsahonkala L, Sillanpaa M, Tuominen J. Social environment and headache in 8- to 9-year-old children: a follow-up study. Headache. 1998;38(3):222-8.

47. Bener A, Uduman S A, Quassimi E M, Khalaily G, Sztriha $\mathrm{L}$, Kilpelainen $\mathrm{H}$, et al. Genetic and environmental factors associated with migraine in schoolchildren. Headache. 2000;40(2):152-7.

48. Laurell K, Larsson B, Mattson P, Eeg-Olofsson O. A 3-year follow-up of headache diagnoses and symptoms in Swedish schoolchildren. Cephalgia. 2006;26(7):809-15.

49. Gillander Gådin K, Hammarström A. School-related health-a cross sectional study among young boys and girls. Int J Health Serv. 2000;30(4):797-820.

50. Bremberg S, Häggman U, Lager A. Ungdomar, stress och psykisk ohälsa-analyser och förslag till åtgärder, Statens offentliga utredningar [Adolescents, stress and psychological illness]. Stockholm: Fritzes; 2006. SOU 2006:77.

51. Miluk-Kolasa B, Obminski Z, Stupnicki R, Golec L. Effects of music treatment on salivary cortisol in patients exposed to pre-surgical stress. Exp Clin Endocrinol. 1994;102:118-120.

Received for publication: 13 November 2006

\section{Appendix}

\section{Questionnaire with five questions administered to the pupils}

Question 1. Is it difficult to hear what the teacher says because of noise in the classroom? a

Question 2. Do you become disturbed in your work because of noise in the classroom? a

Question 3. Do you feel tired because of noise in the classroom? a

Question 4. Do you get a headache because of noise in the classroom? a

Question 5. Is it difficult to read when the classroom is noisy? ${ }^{\mathrm{b}}$

b (1) not difficult, (2) a little bit difficult, (3) rather difficult, (4) difficult, and (5) very difficult. 